\title{
Research on the Status Quo of Yunnan Social Organizations Participating in Community Governance
}

\author{
Mingyang Ruan \\ Kunming University \\ Kunming, China 650214
}

\begin{abstract}
The participation of social organizations in urban and rural community governance is another major measure for the Chinese government to manage the country. From the current situation of social organizations participating in community governance in Yunnan Province, this situation has not yet been formed. This study aims to examine the governance of the social organizations in Yunnan Province, so that the current situation is researched, the existing problems are found, and reasonable countermeasures and suggestions are put forward, in order to provide reference for relevant departments, promote and advocate democratic consultation, finally forming a new pattern of "multiple co-governance".
\end{abstract}

Keywords-social organization; community governance; government purchase

\section{INTRODUCTION}

At present, China's social governance is undergoing a "consensus squeeze" in the transition period. From a macro perspective, this "squeeze" is a contradiction between the people's growing need for a better life and the development of an inadequate balance; at the micro level, there is a contradiction between the grand bureaucratic system and administrative system brought about by excessive intervention in the social and economic fields of the "all-round" government and relatively insufficient social services development. Therefore, at present, Yunnan provincial government and civil affairs departments mainly face two challenges: first, providing institutional thrust, policy support, and lack of capacity building for social and economic development; second, during the transition period of social governance, society needs government to establish service, responsible and responsive concepts and systems, accurately define their roles and perform their due functions. It's necessary for the government to avoid from being offside and absent, and achieve that government, society and market share their respective positions. In view of this, the government and academic circles have reached a consensus on "multiple subjects participate in social governance and entrust professional affairs to professional teams." Therefore, the research intends to analyze the status quo of social organizations participating in community governance in Yunnan Province from the perspective of government civil affairs departments, foundations, and social service organizations to summarize the results of typical pilots, and seek the integration of multi-subjects to participate in cogovernance. Finally, the countermeasures and suggestion will be given.

\section{ThE STATUS QUO OF SOCIAL ORGANIZATIONS PARTICIPATING IN COMMUNITY GOVERNANCE IN YUNNAN}

Judging from the practice of social organizations participating in community governance across the country, the basis of the "multiple co-governance" model is the volume of social organizations. The larger the scale, the more intense the market competition for social services, and in response, its professionalism, diversity and precision will be stronger. What's more, it will have more development possibility in the future. Overall, as of December 31, 2016, the total number of social organizations registered with civil affairs departments at all levels in Yunnan Province was 22,552. Compared with the base figure of 2012 (15603), a total of 6,949 were added in 4 years, with an average annual increase of $7.39 \%$ in "Fig. 1". 


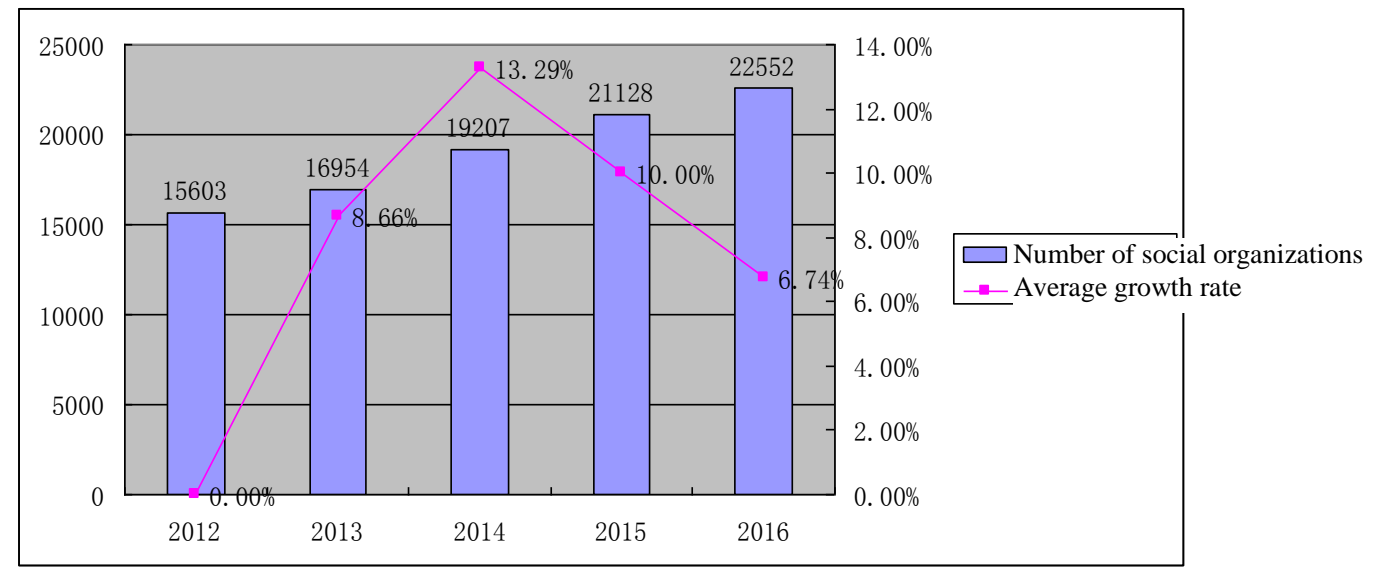

${ }^{\text {a. }}$ Source: Yunnan Statistical Yearbook 2017

Fig. 1. Trends in the scale of social organizations in Yunnan Province from 2013 to 2016.

Compared with other provinces in the same period, the top three social organizations in the 31 provinces and autonomous regions (municipalities) were Jiangsu (84094), Guangdong (59455) and Shandong (45963), and the number of social organizations in Yunnan ranked 13th, 4th in the entire western region and 3rd in the Southwest, next only to Sichuan (39448), Guangxi (239.28 million) and Gansu (22763). In general, the scale of social organizations in Yunnan Province is at the national upper-middle level. Therefore, only for the indicator of scale, the participation of social organizations in Yunnan Province in community governance can be fully developed with favored conditions, but its structure and function need further discussion in "Fig. 2".

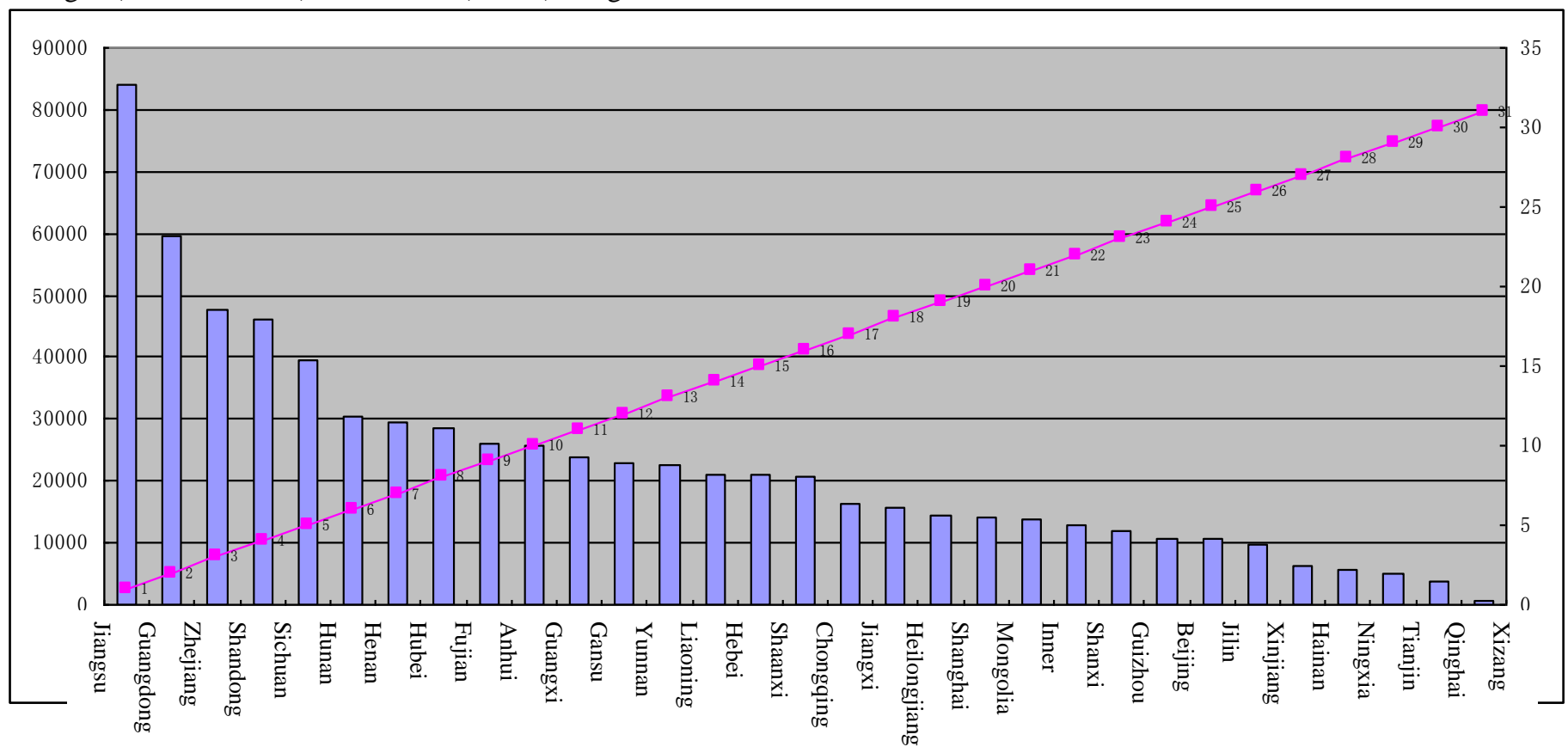

Fig. 2. National Social Organization Size and Ranking in 2016.

From the perspective of the composition of social organizations, there are 14,973 social organizations in the province, accounting for $66.39 \%$ of the total number of registrations, and 7,481 private non-enterprise enterprises, accounting for $33.17 \%$ of the total number of registrations. The scale of the foundation is small with only 98 and all of them are provincial social organizations, accounting for $0.43 \%$ of the total number of registrations in "Fig. 3". 


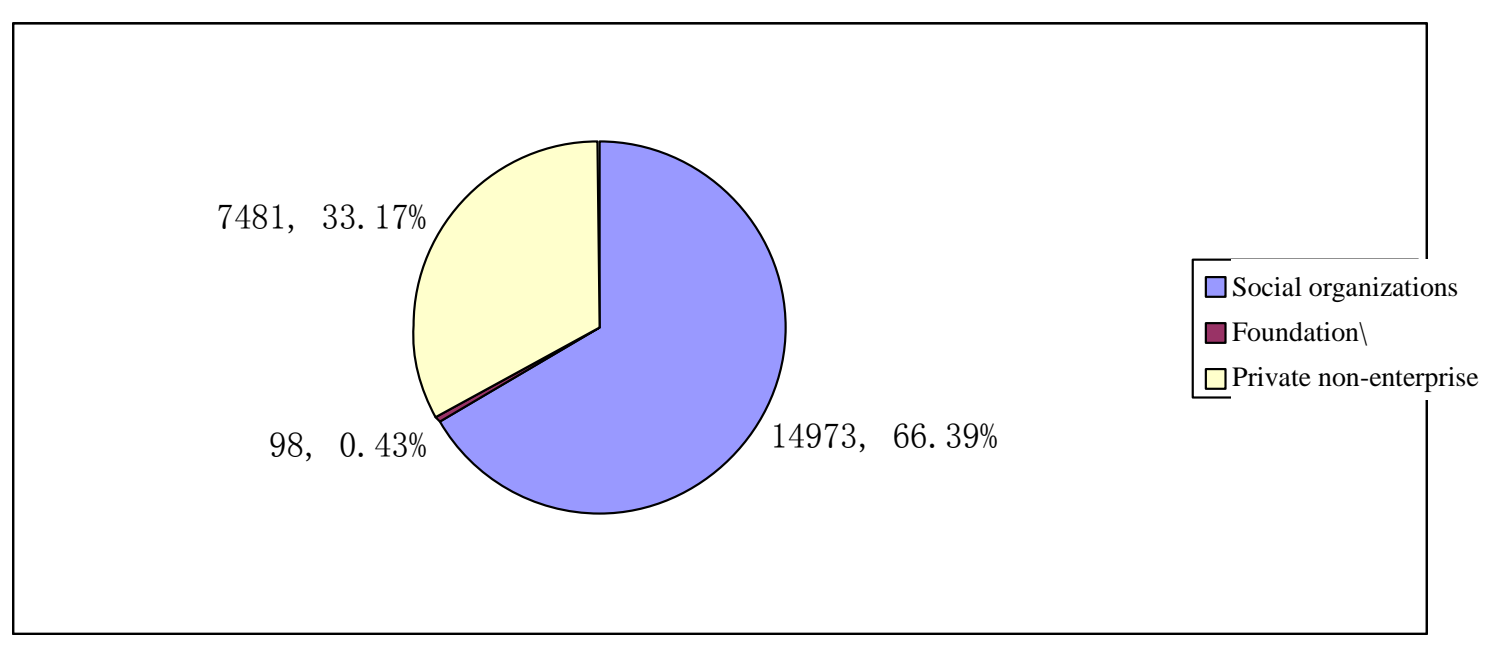

Source: Yunnan Statistical Yearbook 2017

Fig. 3. Composition of social organizations in Yunnan Province.

From the perspective of the hierarchical structure of social organizations in Yunnan Province, as of the end of 2016, there were 1547 provincial social organizations, accounting for $6.86 \%$ of the total number of registrations; 4111 municipal social organizations, accounting for $18.23 \%$ of the total number of registered organizations; 16,894 county social organizations, accounting for $74.91 \%$ of the total number of registrations. In addition, the total number of registrations in NGOs outside the country was 38; the total number of grassroots community social organizations has reached 7,432, accounting for $32.56 \%$ of the total number of registrations. The social organization of all levels in Yunnan Province presents a "pyramid" structure, with the lowest level of social organizations at the provincial level and the largest number of social organizations at the grassroots level. From the perspective of social organizations participating in urban and rural community governance, this structure is relatively ideal, but from the specific practice of Yunnan Province, large-scale county-level social organizations and community social organizations are mainly distributed in business services, while grassroots social organizations specializing in public services are relatively few.

Overall, since 2010, all parts of the country have been actively exploring the reform of the social organization registration management system, and have made efforts in direct registration of social organizations, reduction of registration thresholds and relaxation of registration conditions to create a favorable policy environment for the healthy development of social organizations. The rapid development of Yunnan social organizations in recent years has benefited from the rapid growth of Yunnan's economy and the orderly advancement of the government's innovative social management, as well as the active exploration of supporting the cultivation of social organizations, creating a good environment for the development of social organizations. At the same time, in 2012, Yunnan Province issued the "Yunnan Provincial Industry Association Regulations", which abolished the business associations of the industry associations, relaxed the entry barriers, and realized the direct registration of industry associations, thus enabling the rapid development of industrial and commercial service social organizations. However, it is worthy of reflection that among the various social organizations in Yunnan Province, social organizations that have been named "Chamber of Commerce," "Society," "Association," "Seminar" "Federation," and "Promotion" have occupied half of the total number. Due to the high threshold for approval, the number of foundations that support and supervise community governance and social services has grown sluggishly. What is more serious is that the proportion of social organizations in social services is seriously low and underdeveloped.

\section{THE MAIN DILEMMA OF SOCIAL ORGANIZATIONS PARTICIPATING IN COMMUNITY GOVERNANCE IN YUNNAN PROVINCE}

\section{A. The Pattern of Social Organizations Participating in Community Governance in Yunnan Province Has Not yet Formed}

Overall, the pattern of participation of social organizations in Yunnan Province in community governance has not yet taken shape. Through literature search and web search, the study found that despite that relying on the central finance, civil affairs departments, China Foundation for Poverty Alleviation, China Children's Development Foundation and international NGOs, there are social work projects for special groups such as the urban migrants, disabled people, rural poor people, children in distress, drug users and HIV-infected people in some urban areas and remote rural areas in Yunnan, but these projects have special, temporary and phased characteristics. Judging from the conventional projects that can cover urban and rural communities, in the provinces and municipalities, at the municipal and prefecture levels, no specific practices have been found in which governments purchase social organization services to participate in community governance, or there are reports on social organizations participating in urban and rural community governance. After the "Proposal on Strengthening and Improving Urban and Rural Community Governance" was issued by the Provincial Party Committee and the Provincial 
Government of Yunnan Province, no city or prefecture government including Kunming City has introduced any policy documents for purchasing social organizations to participate in community services. At the county-district level, only the Xishan District and Guandu District of Kunming City have completed the system construction and relied on the service platform for actual operation. This phenomenon does not match the status of Yunnan Province as a major social organization in the country and the status of a strong province in the western region.

\section{B. Limited Financial Support}

At present, the financial investment of social organizations at all levels in Yunnan Province is far from meeting the development needs of social organizations. There is no special development fund for social organizations at all levels of finance, and the government has yet to explore further in terms of entrusting social organizations, purchasing services, and project bidding. Since 2012, the Ministry of Civil Affairs and the Ministry of Finance have allocated a special fund of 200 million Yuan to set up "the central government to support social organizations to participate in social service projects" since the beginning of the year, which are mainly used for social organizations to undertake government social service pilots, and the government- supported private social work service demonstrations and capacity empower of social organizations. There will be 6 to 7 million Yuan each year to be allocated to support social organizations in Yunnan Province to participate in social services, but the supporting project funds have not been implemented in all levels of the budget. At the same time, due to the lack of a strong social welfare atmosphere, the strong sense of charity, and the low trust of social organizations, when all sectors of society donate to social organizations, the enthusiasm is not high, and the funds donated are small and the frequency is low. In addition, because of the irregular operation of a few social organizations, misuse of funds, black-box operations, etc., the public's trust in social organizations has been reduced, resulting in a lack of enthusiasm for the public to donate funds to social organizations. The survival of social organizations is facing a huge test. .

\section{Lack of Organizational Security}

Although the civil affairs department of Yunnan Province has established a three-level review, registration and filing system covering "provincial, municipal (prefecture), county (district)", and the civil organization bureau is responsible for the registration management and annual inspection of social organizations, its functions of coordination and service are weak while the management and supervision functions are strong. In order to avoid the bad situation of "the chaos of decentralization, the malfunction of control", in September 2013, Yunnan Foreign Affairs Office, Friendship Association, and Civil Affairs Department, the Provincial Communist Youth League Committee, the Women's Federation, the Federation of Industry and Commerce, and the CCPIT led the establishment of a platform organization for social organizations in Yunnan Province: Yunnan Provincial Civil Society and Social Organizations International Exchange Promotion Association (referred to as "Yunnan Promotion Association"). In terms of the existing composition of
"Yunnan Promotion Association", its main members are chambers of commerce, scientific research, education, health, law and sports departments. The proportion of social service organizations is less than 5\%. Therefore, there is a large deviation in the goal orientation from the social services of public welfare, volunteerism and service, which has no effect on promoting the participation of social organizations in urban and rural community governance. On the whole, Yunnan Province lacks relevant departments to guide and coordinate the service provided by social organizations at the provincial, municipal, district and county levels. Due to the lack of organizational system, the participation of Yunnan social organizations in governance cannot be guaranteed. The Municipal Party Committee and the Municipal Government of Kunming recently had the idea of setting up "social work committees" to coordinate social work services and urban and rural community governance, but for from Kunming to Yunnan Province, and then provincial departments promotes and spreads it across the province, there is still have a long and hard way to go.

\section{One-dimensional Social Work, Lack of "Output" Thinking}

As "Yunnan Model" mentioned above, in the process of evolution and development, Yunnan social organizations have became "special public welfare model" inertia for special public welfare groups and poverty-stricken areas. In the near future, the social service projects of social organizations supported by central government to participate in social service, China Poverty Alleviation Fund, Red Cross Society and other international NGOs also tend to choose social organizations that can engage in "frontier, poverty, special population" services in project approval. Therefore, this trend has not been weakened, but has been increasingly intensified. The study believes that this trend has serious self-limitation: the provision of services by special social organizations to special groups and regions is a one-dimensional social work.

With the gradual deepening of China's "One Belt, One Road" and "Poverty Alleviation" national strategy, Yunnan Province, as a bridgehead for Southeast Asia and South Asia in the western frontier region, is characterized by "beyond the frontier." Urban and rural residents and local governments are increasingly calling for social organizations to participate in urban and rural community governance. However, due to the narrow scope of their own services objects, the social work transformation in Yunnan Province faces enormous challenges. Of course, in the micro-practices of urban and rural social work, especially rural social work, the policies and concepts advocated by the state, such as "village revitalization, precise poverty alleviation", community-based development and reengineering initiated by international social organization, and livelihood development, are beneficial to the transformation and development of Yunnan social organizations, but for Yunnan local social organizations, the service content, service areas, service targets and link resources have undergone tremendous changes. The transformation from original temporary and staged social work to the routine social work of the sustainability covering urban and rural areas requires a transitional adaptation. 
Nevertheless, the study believes that the "Yunnan model" is a highly specialized and characteristic social work. Its adaptability to "frontier, nationality and poverty" is very strong, and it has the value of copying and promoting. Under the strategic layout of "One Belt, One Road", Yunnan's "powerful" organizations should consider jumping out of the local "circle" and exporting to other frontier regions or South Asia and Southeast Asia.

\section{E. Lack of Effective Linkage Mechanisms Between Government Agencies, Foundations and Service Project Implementation Agencies}

Although the government agency and foundation are all as the social work organizations, the choices of social service projects of both sides have their own value concepts and evaluation mechanism. From the perspective of value concept, government departments at all levels first focus on the political significance, promotion value and social impact of the project. Secondly, they pay attention to the effectiveness, stability and continuity of the project. Finally, they attach the importance on the presentation of the project. Whether the results reported conform to the government's discourse framework tend to be used to measure the quality of the implementation results; the foundation pays more attention to the depth and "temperature" of project execution; whether the goal achieved in reality is consistent with the expected goal; whether the client benefits and whether it realizes its original attention of charity. From the perspective of the evaluation system, the existing government departments (Xishan District and Guandu District) adopt an expert review system, which has stricter regulations on the service content, account management and financial system of the project executing agency, but in the process of implementation, there are not many interventions of the implementing agencies; and the foundations, especially the international non-governmental organizations, have a complete scientific evaluation system for the evaluation of the project. There is a set of standardized supervision and feedback mechanisms before, during and after the implementation of the project. In order to ensure the smooth completion of the project, there are interventions and supervisions during the implementation process. In the project evaluation, feedback and summary, the benefits of the service objects are more valued.

In order to seek their own production and development, social service organizations often undertake projects that are supported by government contracting and foundations. At this time, there will be a "multiple command" situation. Based on the differences in value concepts and evaluation mechanisms, service organizations are often caught in an embarrassed situation that don't know who they should listen to. At the same time, because the foundation is under the supervision of government civil affairs department, there is no attempt to coordinate and interact with each other, and there is no dialogue on social organizations participating in community governance. Nevertheless, the study believes that there is a "limited" consensus between government departments and foundations. For example, government departments can listen to the voices of beneficiaries and evaluate projects in a more scientific and objective way; it is necessary for foundation to pay attention to the promotion value and popularization significance of the project. While taking into account the "special" project, the foundation should consider taking into account the social work projects for the development of urban and rural communities, and seek the intervention and subsidy of the work model. Meanwhile, the shift to pure subsidy should also be considered.

\section{F. Professional Team Development Is Difficult}

From the perspective of the development of social organizations, the proportion of social service-oriented social organizations in Yunnan Province is seriously low with only $4.67 \%$, and the situation of "scatterings, small, weakness" is very common. From the perspective of the type of service organization, the social organizations involved in community governance are almost all practical social work institutions. The hub-type, support-type, platform-type and export-oriented social organizations are seriously lacking. The service-oriented social organizations in Yunnan Province are impeccable in the social work service profession, but it does not pay much attention to its strategic planning, brand building, public relations marketing, financial management, and financing channel construction. Small and medium-sized social organizations do not even have the awareness and ability to touch these aspects.

From the perspective of social work talent construction, as of the end of 2017, there were 48,000 social work talents in Yunnan Province, and there were only 2,766 certified social workers in the province. The number of certified employees was only $5.76 \%$, and the Care Service Center of Yunnan Lianxin Community made the survey of the social work industry and the results showed that the salary of social workrelated employees in Yunnan Province is only between 2,000 and 3,000 Yuan. Due to the low salary of the employees, the brain drain of the industry is serious.

From the perspective of the development of the volunteer team, as of the end of 2016, the total number of registered volunteers of the Yunnan Volunteers Association was 1.73 million, and there were more than 6,000 volunteer service stations covering 16 cities in Yunnan Province. The main areas of service are: "Sunshine Action" for the disabled group, "Qicai Actions" to promote the care of children of migrant workers, volunteer service for large-scale games, emergency rescue volunteer service, anti-drug and anti-AIDS service activities, and volunteer poverty alleviation relay plan of cooperation between Shanghai and Yunnan and volunteer service for the elderly. However, it is regrettable that the volunteer service provided has not been oriented to the community, nor has it formed a linkage mechanism with community social workers. At the same time, the mobilization of volunteers in Yunnan Province has not formed a long-term mechanism, and the feature of temporary and sports mobilization is relatively strong, so that there are large gaps when compared with other regions.

\section{G. The Ecological Homogenization of Social Work Is Serious}

The homogenization of professional social organizations engaged in social work in Yunnan Province is very serious. From industry giants to small and medium-sized social organizations, almost all of them are engaged in serviceoriented practical social work. Market segmentation and 
differentiated competition are almost blank. Not only that, there is "mountain-stronghold mentality" in the social work circles of Yunnan Province. While large-scale organizations monopolize the industry, they continue to accelerate their own division and occupy the living space of other small social organizations. Nevertheless, with the participation of social organizations in community governance as an opportunity, if the government can correctly guide and seek breakthroughs in the construction of export-oriented, platform-based, supportoriented, consulting-based and research-oriented social organizations, it can be expected to enhance the diversity of services and improve the differentiation of the service system in the future.

\section{COUNTERMEASURES AND SUGGESTIONS}

\section{A. Constructing a New "Multi Level and Multi Center" Pattern of Urban and Rural Governance with the Government as the Leading Factor}

The civil affairs department of Yunnan Province and relevant government departments should dare to try first, be brave in innovating the institutional environment, and carrying out the top-level design for Yunnan social organizations participating in the social management to build a new "multilevel, multi-center" pattern of urban-rural governance with government leading.

Specifically, first, at the vertical level, a social work committee (referred to as the "Social Work Committee") should be established to coordinate community governance. Taking the preparatory establishment of the "Social Work Committee" of Kunming as an opportunity, the pilot experience of the "Xishan Model" and "Guandu Mode" shall be promoted throughout the province. Through top-down driving and bottom-up testing, within three to five years, the four-level cover of social work committees (provincial, municipal, county, and street) will be formed to comprehensively coordinate the "three social communities linkages" and social governance work.

Second, at the horizontal level, a new pattern of "multiple co-governance" should be formed. It's necessary to regard the city, district, street and community comprehensive Party committee as the core, the community building actions as the basis, various levels of social organization incubation base, social work personnel cultivation center and community workstations as management service platform to build a kind of new mechanism with the co-participation of social groups, private non-enterprises, foundations enterprises, social workers, volunteers and urban and rural residents and finally form a new pattern of grassroots governance of "party committee leadership, government responsibility, social coordination, public participation, and rule of law guarantee".

\section{B. Introducing Supporting Policies and Attaching Importance to Pilot Work}

First, in the overall design aspect, the social organization's participation in social governance as a key content should be included in the "five-year" plan for the development of social organizations in Yunnan Province, and the overall and staged goals of social organizations' participation in community governance shall be clarified. With the help of the strength of universities and research institutions, the policy environment for social organizations participating in community governance in Yunnan Province and specific practices, the policy research should be carried out to put forward practical and feasible countermeasures, and introduce relevant policies for cultivating social organization development and purchasing government and community service projects.

Second, in financial support, it's necessary to integrate the strength of Yunnan group organizations, foundations, chambers of commerce, and social groups to establish the Yunnan Provincial Social Organization Foundation, and allocate funds to promote social organizations to participate in community services; the Welfare Lottery Project should be "inclined" to basic public services, especially community service areas" "It is recommended that the annual public welfare fund project should support community governance projects with the funds not less than $30 \%$ of the total amount; governments at all levels should implement the "Special Fund for Cultivating and Developing Social Organizations" in the budget. It's wise to foster the development of social organizations by supporting projects and support the priority development of "four types of social organizations" and focus on supporting the development of service-oriented social organizations and community social organizations.

Third, Pay attention to the pilot experience. It's necessary to summarize the advanced experience of social organizations participating in the development of urban and rural communities, establish the success stories of community governance in urban communities, rural communities, and urban-rural integration areas, recognize individuals and organizations in community work, and create a good atmosphere for community-wide attention to community governance and enhance social influence and reputation of social organizations.

\section{Creating a Social Organization Development Platform of \\ "Trinity" and Establish a Community Social Organization Classification Evaluation Mechanism}

First, for the overall layout, it's important to establish the ruling philosophy of "less domination, more governance" and transfer government functions relying on the power of civil affairs departments at all levels or the "Social Work Committee" to purchase social organizations in the form of projects, and comprehensively promote the "third sector" forces to participate in Yunnan community governance. Moreover, it's necessary to comprehensively promote the construction of four levels of social organization incubation bases in provinces, cities, districts and counties, and gradually complete the construction of social organization cultivation systems at all levels within three to five years through pilotadvanced measures, and build social organization development platform integrating social organization cultivation and development, social worker training and the community social work project implementation in the "three-in-one" way.

Second, for platform construction, (1) Establishing the advanced concept of "social organization service social organization" and introducing "platform-type" organization to provide professional strategic planning services for civil affairs departments or social work committees at all levels, and to 
serve and manage the organizations that have settled in and hatched, provide services such as consultation, supervision and resource links; (2) establishing a "third-party evaluation" mechanism. It's conducive to rely on relevant government evaluation departments, experts and scholars, international NGOs, social workers and professional evaluation agencies to evaluate service organizations and project implementation, perform strict project management for project declaration, mid-term inspection and settlement; (3) Introducing capacitybuilding team. The team shall be responsible for brand building, promotion, financial management and professional supervision of resident and incubating institutions.

Third, establish a classified evaluation mechanism for the resident organization. In view of the specific practice of social organization incubation bases in China, it can be divided into three categories. The first category is large and medium-sized specialized social work organizations. These organizations have rich experience and professional work patterns, but generally have no strong reliance on project funds. Such organizations should be positioned to that implement specific projects while providing coordination and supervision services to other weak organizations. According to the principle of "can enter and exit", after 2-3 years of operation, they should take the initiative to withdraw or switch to the platform work; the second category is the weak or nascent professional social work institutions, which should be evaluated by the third-party evaluation agency to decide whether to settle or incubate. Those that have the project execution ability and be qualified are allowed to enter, and the institutions with insufficient capacity should enter the "the social organization incubator" to carry out capacity improvement, and after the training, it will be decided whether to settle in or not; the third category is social community self-governing organizations. Such organizations are not strong in project funding reliance, but their professional ability is relatively low. They should rely on the "social organization incubator camp" for professional supervision and carry out training regularly to strengthen the pairing and co-construction with other organizations.

\section{Promoting the Construction of the Social Worker Team and Enhancing the Sense of Industry Presence}

First, in the overall planning aspect, it's indispensable to attach importance to the construction of the talent team, incorporate the training of social workers into the talent development plan at all levels, formulate special community and social work talent development plans, promote the scale growth of the employees in entire industry, and rely on the government to purchase services to train social workers for qualifications and significantly increase the rate of employment of certified social workers.

Second, in the aspect of remuneration, governments at all levels should learn from the experience of advanced regions, establish salary standards for local social workers in accordance with their own economic development level, and strive to improve the remuneration packages of community cadres and social workers, reduce the loss of employees to enhance the sense of professional presence and attractiveness.

Third, for talent training, it's essential to rely on the "think tank" resources of colleges and universities in Yunnan
Province to create a social organization or social work college that integrates "training study, qualification examination, consultation and supervision", and regularly conducts training for village and social cadres, social work personnel and related employees. Through the project-oriented "link" way, the community cadres should be implanted the professional social work concepts, so that social organizations and social workers are familiar with "government discourse", thereby further enhancing the effectiveness of the "three social community linkages."

Fourth, for the "duplex" linkage, volunteers are the backup force of social workers. It's vital to continue to strengthen the "duplex" linkage mechanism of "social workers + volunteers", use social workers to promote volunteer services, and further expand the scale of volunteer teams in Yunnan Province to establish a long-term mobilization mechanism for volunteer services. Yunnan Provincial Volunteers Association can be regarded as a carrier to cultivate urban and rural community service projects and guide volunteers to participate in urban and rural community governance.

\section{E. Improving Management Mechanism and Pursuing Collaborative Governance}

First, establish an in/post-event supervision system for social organizations, and do a good job of "decentralization" and "management". So, it is necessary to raise the awareness of supervision, implement regulatory responsibilities, and change the situation that attach importance on pre-review and re-examination, but look down on in/post-event supervision, as well as unclear rights and responsibilities; to change the way of supervision with the support of relevant national laws and regulations and strengthen law enforcement with thinking and way of nomocracy. In addition, it's advisable to rely on the construction of a social credit system to strengthen the supervision of social organizations, and introduce third-party assessments to improve the supervision of social organizations.

Second, build a collaborative governance structure. Take the opportunity to actively explore the modern social organization management mechanism system, the partnerships with organizations such as group organizations, foundations, chambers of commerce, research institutions, and social work organizations should be set up to achieve non-intervention, no "offside". Besides that, it is necessary to establish a joint conference system to promote deliberative democracy and explore a new situation of "multiple co-governance and coordinated governance."

Third, establish a performance-based government. Through the sharing development with the industry, the government can clarify its own boundaries, and it should gradually transform from a "all-inclusive" all-round government to a performanceoriented government that provides the most core and most advantageous public service products, focusing on creating an equal competitive environment and providing services for the market and social entities in the process of building a pluralistic and socialized public service supply system.

\section{CONCLUSION}

In summary, the study believes that the participation of social organizations in community governance is a technical 
political act. As a technical solution, it is necessary to achieve the goal through certain institutional design. This requires both top-down design and bottom-up practice, and requires government, universities, social organizations, social enterprises, social workers, and communities participating. As well as the volunteer's own concept awakening and professional construction, it is also necessary to launch and educate all parties involved in the pluralistic governance system.

\section{REFERENCES}

[1] Mao Shoulong, Li Mei, Chen Youhan. The Governance Reform of Western Governments [M]. Beijing: China Renmin University Press, 1998.

[2] Yu Keping. Governance and Good Governance [M]. Beijing: Social Sciences Academic Press, 2000.

[3] Yu Keping. On the Modernization of State Governance [M]. Beijing: Social Sciences Academic Press, 2014.

[4] Wang Ming. Social Organization and Social Governance [M]. Beijing: Social Sciences Academic Press, 2014.

[5] Ma Guofang. Empirical Research on the Development of Social Organizations - Based on the Perspective of Social Governance [M]. Beijing: Social Sciences Academic Press, 2017.

[6] Kang Xiaoguang et al. NGO and Government Cooperation Strategy [M] Beijing: Social Sciences Academic Press, 2010.

[7] Liu Zhongxiang. Foundation Blue Book: China Foundation Development Report (2013) [M]. Beijing: Social Science Literature Press, 2014.

[8] Shen Ronghua, Zhou Yicheng. The Theory of Good Governance and the Limited Orientation of China's Government Reform[J]. Theoretical Discussion, 2003(05).

[9] Chen Guangsheng. Going to Good Governance [M]. Hangzhou: Zhejiang University Press, 2007.

[10] Zhou Hongyun. National Governance Assessment: China and the World [M]. Taipei: Central Compilation Press, 2009.

[11] Wang Puqu, [US] Lester M. Salamon. The Research on Government Purchasing Public Services from Social Organizations [M]. Beijing: Peking University Press, 2010.

[12] China National Bureau of Statistics. China Statistical Yearbook 2017 [M]. Beijing: China Statistics Press, 2017. 